\title{
Inserção das lutas na educação física escolar da cidade de Muriaé-Mg ${ }^{1}$
}

\section{Insertion of fights in school physical education in the city of Muriaé-Mg}

\section{Inserción de las luchas en la educación física escolar de la ciudad de Muriaé-Mg}

\author{
iD (9) Nicoly Rocha Ferreira \\ Centro Universitário Faminas, Muriaé, Minas Gerais, Brasil \\ E-mail: nicoly.999@hotmail.com \\ iD Júlia Loth Costa \\ Universidade Federal de Juiz de Fora, Juiz de Fora, Minas Gerais, Brasil \\ E-mail: julia.lothc@gmail.com \\ iD Tassiana Aparecida Hudson \\ Centro Universitário Faminas, Muriaé, Minas Gerais, Brasil \\ E-mail: tassianahudson@hotmail.com \\ iD Juliana Fernandes Filgueiras Meireles \\ Kennesaw State University, Kennesaw, Georgia, EUA. \\ E-mail: eujuly90@hotmail.com
}

\begin{abstract}
Resumo: O objetivo deste trabalho foi verificar se os professores de Educação Física escolar utilizam o conteúdo Lutas em suas aulas na cidade de Muriaé - MG. Participaram da pesquisa sete professores de educação física de escolas públicas e privadas. Foi aplicada uma entrevista semiestruturada e os dados foram analisados através da Análise de Conteúdo. Observou-se que apenas dois professores desenvolvem o conteúdo lutas em suas aulas. Falta de preparo e conhecimento foram apontados como os principais motivos para a não abordagem desse
\end{abstract}

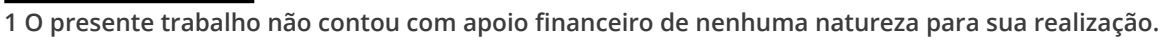


conteúdo nas aulas. Concluiu-se que as lutas ainda são pouco utilizadas nas aulas de Educação Física escolar e que a formação de professores é um ponto chave para a solução dessa defasagem.

Palavras-chave: Educação Física Escolar. Lutas Corporais. Pesquisa Qualitativa.

Abstract: The objective was to verify if teachers of Physical Education at school use the content Fight in their classes in the city of Muriaé MG. Seven physical education teachers from public and private schools participated in the research. A semi-structured interview was applied and the data were analyzed through Content Analysis. It was observed that only two teachers develop the content fights in their classes. Lack of preparation and knowledge were pointed out as the main reasons for not addressing this content in class. It was concluded that the struggles are still little used in school Physical Education classes, and that the training of teachers is a key point for the solution of this gap.

Keywords: School Physical Education. Body Fights. Qualitative Study.

Resumen: El objetivo fue verificar si los profesores de Educación Física en la escuela utilizan el contenido Lucha en sus clases en la ciudad de Muriaé - MG. En la investigación participaron siete profesores de educación física de escuelas públicas y privadas. Se aplicó una entrevista semiestructurada y los datos se analizaron mediante Análisis de Contenido. Se observó que solo dos docentes desarrollan las luchas de contenido en sus clases. La falta de preparación y conocimiento fueron señalados como los principales motivos para no abordar este contenido en clase. Se concluyó que las luchas aún son poco utilizadas en las clases de Educación Física escolar, y que la formación de los docentes es un punto clave para la solución de esta brecha.

Palabras Clave: Educación Física Escolar. Peleas Corporales. Investigación Cualitativa.

Submetido em: 15-02-2021

Aceito em: 16-09-2021 


\section{Introdução}

A Educação Física escolar objetiva ensinar a cultura corporal historicamente construída, a partir de conteúdos norteadores: as Brincadeiras e os Jogos, os Esportes, as Ginásticas, as Danças, as Lutas e as Práticas corporais de aventura (BRASIL, 2017). Para Rufino e Darido (2015), cabe ao professor possibilitar a vivência desses conteúdos para que seja possível uma reflexão crítica sobre as diferentes práticas ao seu redor. A Educação Física escolar vai além do ensino do gesto motor correto que, por sua vez, também não pode ser desconsiderado (BATISTA; MOURA, 2019). Assim, o professor deve problematizar, interpretar, relacionar e analisar com seus alunos as amplas manifestações da cultura corporal, de tal forma que estes compreendam os sentidos e os significados das práticas corporais.

Os Parâmetros Curriculares Nacionais (PCNs) e a Base Nacional Comum Curricular (BNCC) são documentos norteadores que indicam uma sistematização de conteúdos a serem desenvolvidos na Educação Física escolar (BRASIL, 1998; 2017). As lutas estão presentes nesses documentos, os quais orientam sobre como esse conteúdo deve ser trabalhado em todos os níveis da educação básica (RUFINO; DARIDO, 2011).

Os PCNs são um referencial para o Ensino Fundamental e Médio em todo o país, não sendo obrigatório, mas auxilia o trabaIho do professor norteando as atividades que serão realizadas em aula. Seu objetivo é garantir aos alunos o direito de desfrutar dos conhecimentos necessários para o exercício da cidadania (BRASIL, 1998). Nos PCNs, as lutas são definidas como disputas em que os oponentes devem ser subjugados a partir de movimentos específicos das lutas, como, por exemplo, o desequilíbrio e a combinação de ações de ataque e defesa. Ademais, caracterizam-se por uma regulamentação específica a fim de punir atitudes de violência e deslealdade (BRASIL, 1998). 
A BNCC é o documento norteador mais recente e tem como objetivo principal garantir a educação com igualdade por meio das competências fundamentais para a formação do cidadão ao longo da educação básica (BRASIL, 2017). Este documento visa orientar a formulação dos currículos das escolas delimitando os conteúdos que devem ser ensinados em todo o país. No componente curricular de Educação Física, as práticas corporais são divididas em seis unidades temáticas: as Brincadeiras e os Jogos, os Esportes, as Ginásticas, as Danças, as Lutas e as Práticas corporais de aventura (BRASIL, 2017).

Na proposta da BNCC, as lutas são abordadas como categoria da unidade temática "Esporte", descritas como "esportes de combate" e apresentadas também de forma específica como uma das unidades temáticas denominada "Lutas", presente nos anos finais do Ensino Fundamental II. É nessa fase de escolarização que os alunos têm maior capacidade de abstração e de acessar diferentes fontes de informação, e essas características permitem aos estudantes maior aprofundamento nos estudos das práticas corporais na escola. As lutas são descritas como práticas corporais em que os participantes empregam técnicas específicas com diferentes objetivos direcionados ao oponente, incluindo lutas do contexto comunitário e regionais, lutas brasileiras e de outros países (BRASIL, 2017).

Segundo Moura et al. (2019), o conteúdo lutas deve estar presente nas propostas pedagógicas da Educação Física escolar desde a educação infantil até o ensino médio, dado que é uma manifestação da cultura corporal que não pode ser excluída desse contexto. Embora façam parte do eixo curricular, as lutas ainda são pouco ensinadas no ambiente escolar (MOURA et al., 2019). Alguns argumentos são frequentemente utilizados para justificar a ausência do ensino deste conteúdo nas escolas, como incitação a aspectos de violência, a falta de materiais específicos e a ausência de espaços adequados (BARROS; GABRIEL, 2011; RUFINO; DARIDO, 2015). É raro algum professor de Educação Física que, além dos esportes coletivos de quadra (handebol, vôlei, futsal e basquete), trabalhe 
algum conteúdo referente às lutas, o que, de acordo com Moura et al. (2019), é justificado devido à ausência de conhecimento dos professores na área. Todavia, o ensino das lutas na escola não exige do professor conhecimentos de um treinador ou lutador, uma vez que não se trata de formação de atletas. Há a necessidade de que o professor seja um profissional capaz de proporcionar aos seus alunos conhecimentos acerca das lutas enquanto manifestações da cultura corporal de movimento (RUFINO; DARIDO, 2015).

Os jogos de lutas, por exemplo, são práticas criadas com o objetivo de reproduzir golpes e atos das lutas que podem ser trabaIhados nas escolas. Eles auxiliam o desenvolvimento integral do aluno ao propiciar uma comunicação através do contato corporal e dos gestos das lutas (GOMES, 2013; RUFINO; DARIDO, 2015). A ludicidade inerente aos jogos também se faz presente nesse desenvolvimento do aluno, visto que, no universo da criança, a brincadeira proporciona um processo de ensino simplificado tornando possível a aprendizagem (OLIVEIRA et al., 2017). Algumas propostas também incluem a conceituação de algumas modalidades de lutas, a história de determinadas práticas, diferença entre lutar e brigar, curiosidades sobre as lutas, entre outras (RUFINO; DARIDO, 2015). De acordo com Pereira et al. (2020), o jogo pode ser considerado uma ótima estratégia para o ensino das lutas na escola, contribuindo para a quebra de paradigmas sobre o conteúdo.

Somado ao fato que o ensino das lutas no ambiente escolar, em sua maioria, não tem sido abordado de forma satisfatória, existe também uma defasagem de estudos proponentes a respeito dessa temática (LOPEZ; GOLIN; RIBEIRO, 2019). Por isso, o presente estudo tem como objetivo verificar se os professores de Educação Física escolar trabalham o conteúdo lutas em suas aulas, bem como analisar como este conteúdo tem sido desenvolvido por eles, por meio do relato desses professores sobre suas dificuldades, possibilidades e métodos de ensino. 


\section{Métodos}

Trata-se de uma pesquisa de natureza qualitativa, exploratória e transversal (THOMAS; NELSON; SILVERMAN, 2012). O projeto foi aprovado pelo Comitê de Ética e Pesquisa em Seres Humanos do Centro Universitário UNIFAMINAS (parecer número: 3.433.073). Todos os participantes assinaram o Termo de Consentimento Livre e Esclarecido (TCLE), consentindo com a participação voluntária.

A amostra do presente estudo foi composta por professores de Educação Física de escolas públicas e particulares de Muriaé MG. As escolas foram contatadas a fim de solicitar a autorização para a realização das entrevistas. Após autorizada, a pesquisadora responsável estabeleceu contato por telefone com os professores de Educação Física para explicar os objetivos e procedimentos da pesquisa, bem como convidá-los para participar. Todos os participantes foram informados que a entrevista seria gravada em áudio e que seria iniciada após a autorização a partir da assinatura do TCLE. Após a concordância, o dia e horário para as entrevistas foram estabelecidos, vale ressaltar que todas foram realizadas sempre pela mesma pesquisadora e não foi delimitado tempo limite para o término da mesma. A gravação foi realizada com o gravador do aparelho Motorola Moto G6 Play.

Ao todo, foram entrevistados 7 professores de Educação Física de 3 escolas públicas e 2 escolas particulares. A princípio buscou-se selecionar professores de instituições privadas e públicas para que fosse possível coletar informações de instituições com realidades diferentes, cabe destacar que essas instituições de ensino foram selecionadas por conveniência. O tamanho amostral foi considerado a partir do princípio da saturação, no qual a frequência de respostas semelhantes entre os entrevistados se torna um critério para interromper o recrutamento de novos (FONTANELLA; RICAS; TURATO, 2008). Foram incluídos professores de Educação Física em qualquer nível de ensino da Educação Básica e àqueles 
Inserção das lutas na educação física escolar da cidade de Muriaé-Mg

Nicoly Rocha Ferreira • Júlia Loth Costa • Tassiana Aparecida Hudson • Juliana Fernandes Filgueiras Meireles

que não foi possível realizar a entrevista, seja por desistência ou incompatibilidade de horários, foram excluídos.

A coleta de dados foi realizada por meio de uma entrevista semiestruturada, a qual teve como objetivo investigar, sob o ponto de vista dos professores, como a modalidade lutas se insere no contexto escolar na cidade de Muriaé - MG. Esse roteiro continha perguntas destinadas à caracterização da amostra, tais como: idade, tempo de formado e de atuação e nível de ensino em que atua. Ademais, foram incluídas perguntas direcionadas aos conteúdos abordados nas aulas, metodologias utilizadas, compreensão acerca do conteúdo lutas, possibilidades pedagógicas e dificuldades para sua inserção. O roteiro foi submetido à avaliação de cinco professores especialistas em pesquisa qualitativa que deram a sua aprovação para a versão final.

Para a análise dos dados, a transcrição foi feita na íntegra e utilizou-se a técnica de Análise de Conteúdo proposta por Bardin (2011). Em seguida, o material foi explorado e seguindo as diferentes fases da análise de conteúdo: 1) pré-análise - refere-se a operacionalizar e sistematizar as ideias iniciais; 2) exploração do material - consiste na decomposição, codificação ou enumeração dos dados em função de regras previamente formuladas; 3) tratamento dos resultados e interpretação - caracteriza-se pela realização de inferências. A partir da leitura, as falas foram agrupadas em categorias, configurando a análise de conteúdo categórica.

\section{Resultados e Discussão}

Ao todo, foram entrevistados 7 professores de Educação Física, sendo 2 mulheres e 5 homens, cuja idade variou de 25 a 56 anos e o tempo de trabalho no contexto escolar entre 1 e 30 anos. As características descritivas de cada professor entrevistado estão expostas no Quadro 1. 
Inserção das lutas na educação física escolar da cidade de Muriaé-Mg

Nicoly Rocha Ferreira • Júlia Loth Costa • Tassiana Aparecida Hudson • Juliana Fernandes Filgueiras Meireles

Quadro 1- Caracterização da amostra

\begin{tabular}{|cccccc|}
\hline Indivíduo & Idade & $\begin{array}{c}\text { Tempo de } \\
\text { formado }\end{array}$ & $\begin{array}{c}\text { Tempo de } \\
\text { atuação como } \\
\text { professor }\end{array}$ & $\begin{array}{c}\text { Anos escolares de atua- } \\
\text { ção }\end{array}$ & $\begin{array}{c}\text { Escola de } \\
\text { atuação }\end{array}$ \\
\hline P1 & 54 anos & 29 anos & 26 anos & E.F. anos iniciais & Pública \\
P2 & 26 anos & 5 anos & 3 anos & E.F. anos finais & Pública \\
P3 & 42 anos & 15 anos & 15 anos & E.F. anos finais e E.M. & Pública \\
P4 & 56 anos & 31 anos & 30 anos & E.M. & Pública \\
P5 & 26 anos & 5 anos & 2 anos & E.F. anos iniciais & Particular \\
P6 & 25 anos & 4 anos & 2 anos & E.F. anos finais & Pública \\
P7 & 25 anos & 3 anos & 1 ano & E.F. anos iniciais e E.M. & Particular \\
\hline
\end{tabular}

Fonte: os autores (2021).

Legenda: P-Professor; E.F. - Ensino Fundamental; E.M. - Ensino Médio.

A partir da análise das entrevistas, com o intuito de responder aos objetivos do presente estudo, foram criadas três categorias como exposto na Figura 1. Cada uma dessas categorias está retratada e discutida separadamente em seguida.

Figura 1. Divisão das categorias identificadas a partir das falas dos professores

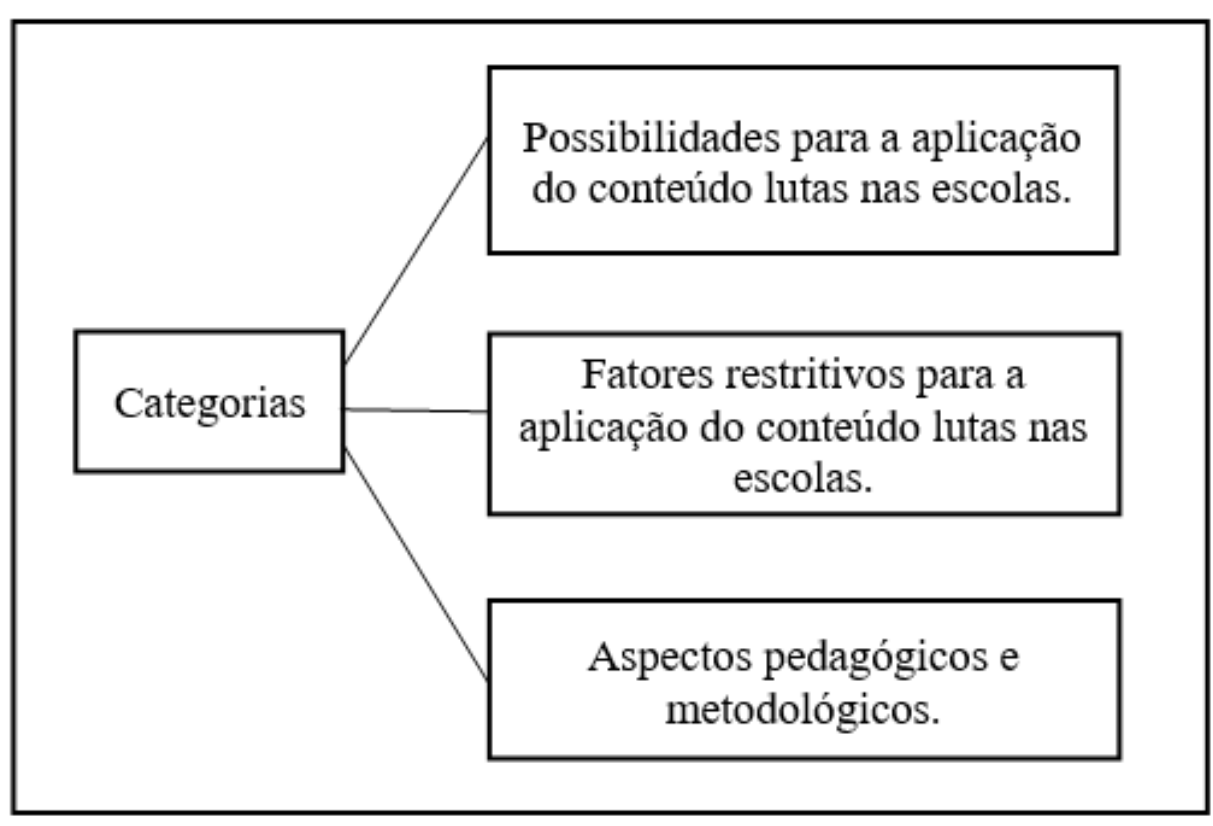

Fonte: os autores (2021). 


\section{Possibilidades para a aplicação do conteúdo lutas nas escolas}

Nesta categoria, buscou-se trazer as possibilidades para aplicação do conteúdo lutas nas escolas de acordo com o relato dos professores entrevistados. Através das entrevistas constatou-se que os professores trabalham o conteúdo lutas nas suas aulas, mesmo que de forma teórica, por vídeos, imagens ou levando os alunos a lugares em que acontecem a prática das lutas, como demonstrado nas falas a seguir: "[...] Possibilidades é apenas no contexto teórico. Convido pessoas de fora para que mostre as lutas aos alunos [...]" (P.1). "[...] Trazer vídeos das diversas lutas para meus alunos [...]" (P.4). "[...] Conhecimento teórico e levar meus alunos até uma academia de lutas para que vivenciem um pouco $[\ldots]^{\prime \prime}(P .7)$.

As aulas teóricas são indispensáveis, pois fornecem aos alunos a compreensão histórica e cultural dos conteúdos, mas cabe ao professor proporcionar aos alunos a aprendizagem das dimensões da Educação Física, estabelecendo uma conexão entre teoria e prática, conforme descrito por Rufino e Darido (2015), o conteúdo lutas pode ser abordado dentro das três dimensões do conhecimento: A Dimensão Conceitual dos conteúdos diz respeito ao "saber", ou seja, o aluno precisa conhecer as diversas modalidades existentes, suas regras e histórias. A Dimensão Procedimental refere-se ao "saber fazer" que é caracterizada pela aprendizagem dos movimentos característicos das lutas. A Dimensão Atitudinal trata-se do "saber ser", ou seja, aos valores e atitudes, abordando questões como, por exemplo: o respeito ao próximo e aos limites do próprio corpo, e reconhecer a diferença entre lutas e brigas (RUFINO; DARIDO, 2015). Durante a prática docente, mesmo que ocorra maior ênfase em um ou outro, as dimensões do conhecimento são indissociáveis. Assim, enquanto se aplica aula prática, realizando exercícios específicos, o professor pode trabalhar todas as dimensões ao explicar sobre os objetivos daqueles movimen- 
Inserção das lutas na educação física escolar da cidade de Muriaé-Mg

Nicoly Rocha Ferreira • Júlia Loth Costa • Tassiana Aparecida Hudson • Juliana Fernandes Filgueiras Meireles

tos, a importância e benefícios para o corpo, bem como sua historicidade e importância para o indivíduo (RUFINO; DARIDO, 2015).

De acordo com Nascimento e Almeida (2007), em alguns casos, as lutas são apresentadas nas escolas por terceiros como forma de projeto ou aula extra oferecida ao aluno como disciplina optativa e, em escolas particulares, apresentam um custo adicional. Neste caso, as lutas são abordadas como se fosse um conteúdo alheio à disciplina de Educação Física e do Projeto Político Pedagógico da escola. Conforme relatado por um dos entrevistados, esta parece ser uma prática recorrente: "[...] O colégio disponibiliza um professor de lutas, onde é uma disciplina optativa com um valor a ser pago a parte e que ocorre em contraturno [...]" (P.5).

O conteúdo lutas é abordado nos PCNs (BRASIL, 1998) como componente da cultura corporal que deve ser tratado nas aulas de Educação Física escolar de maneira lúdica. Sendo assim, o professor de Educação Física escolar é o profissional mais indicado, visto que as lutas ensinadas por professores especialistas em lutas, por exemplo, podem priorizar os aspectos técnicos e à padronização de movimentos em detrimento de uma aprendizagem integral do conteúdo e uma reflexão crítica, afastando-se da essência da proposta das lutas na Educação Física escolar. Nascimento e Almeida (2007) apontam maneiras de como iniciar o conteúdo lutas em sala de aula, que pode ser por meio de uma apresentação teórica e diálogo com os alunos para que relatassem as experiências e conhecimentos sobre o conteúdo, de maneira que as aulas possam abranger também o conhecimento prévio do aluno e o seu contexto.

De acordo com Gomes et al. (2013) e Lopes e Kerr (2015), as lutas podem ser introduzidas no contexto escolar a partir de jogos que dispõem de elementos das lutas. Algumas formas de abordagem do conteúdo lutas foram relatadas pelos professores: “[...] Trabalho com as lutas de forma recreativa por exemplo, realizo briga de galo, faço cabo de guerra, são exercícios de adaptação em termos de combate, disputa [...]" (P.3). 
Inserção das lutas na educação física escolar da cidade de Muriaé-Mg

Nicoly Rocha Ferreira • Júlia Loth Costa • Tassiana Aparecida Hudson • Juliana Fernandes Filgueiras Meireles

Um fator importante na inclusão das lutas nas escolas diz respeito ao desenvolvimento de valores como a autoconfiança e a coragem (UENO; SOUZA, 2014). Dentre os professores entrevistados, um deles, que além de ser praticante também ministra aulas de caratê, relatou sobre valores, ações e hábitos desenvolvidos através das lutas e a importância de incluir este conteúdo em seu planejamento:

[...] é um conteúdo que não fica de fora do meu planejamento de forma nenhuma e destaco dois fatores para isto, é uma modalidade que trabalha a concentração e o mais importante para mim em termos de lutas que é a disciplina, isso, sem dúvidas, ajudará os alunos nas demais matérias [...] (P.3).

Embora o conteúdo lutas seja componente obrigatório da Educação Física escolar (BRASIL, 2017), dos 7 professores entrevistados apenas 2 abordam de forma completa em suas dimensões conceituais, procedimentais e atitudinais. É preciso que todos os conteúdos, assim como as lutas, sejam abordados e explorados em todas as dimensões do conhecimento para garantir uma aprendizagem completa.

\section{Fatores restritivos para a aplicação do conteúdo lutas nas escolas}

Nesta seção, buscou-se destacar ao longo das falas dos professores alguns fatores que dificultam o ensino das lutas nas escolas. Para Nunomura (1998), conteúdos como ginásticas, lutas, danças, entre outras, são quase inexistentes no ambiente escolar, muitas vezes essa ausência é justificada pela falta de materiais específicos, como no estudo de Costa et al. (2019), por exemplo. Rufino e Darido (2015) destacam que a ausência ou escassez de equipamentos específicos para a prática dificulta a aplicação desses conteúdos na Educação Física escolar, como pode ser verifica- 
Inserção das lutas na educação física escolar da cidade de Muriaé-Mg

Nicoly Rocha Ferreira • Júlia Loth Costa • Tassiana Aparecida Hudson • Juliana Fernandes Filgueiras Meireles

do na fala de um dos professores:" [...] Os materiais para a prática são escassos [...]" (P.2).

Outro fator que foi apontado pelos professores como empeciIho é a falta de conhecimento sobre o conteúdo. Segundo Moura et al. (2019), em sua revisão de literatura, os obstáculos em abordar as lutas nas escolas são provenientes, em partes, da formação do professor de Educação Física, como apresentado em alguns relatos: "[...] falta de conhecimento específico da minha parte [...]" (P.1). "[...] a falta de conhecimento da minha parte, tenho uma compreensão vaga, apenas sei o que foi ensinado na faculdade [...]" (P.5). "[...] minha falta de conhecimento sobre como trabalhar este conteúdo nas aulas [...]" (P.7).

Ainsegurança ao tratar do conteúdo lutas é uma das causas que dificulta sua inclusão nas aulas de Educação Física (NASCIMENTO; ALMEIDA, 2007; RUFINO; DARIDO, 2015). Contudo, se este conteúdo faz parte da cultura corporal, ele deve ser tratado no ambiente escolar de forma integral e possibilitar à criança e adolescentes experimentarem e refletirem sobre os diferentes tipos de movimentos pertencentes às lutas, proporcionando aos alunos uma apropriação do conteúdo como prática corporal (OLIVEIRA et al., 2017).

Conforme relata Alencar (2015), as modalidades de lutas, apesar de fazerem parte da matriz do eixo curricular ainda são pouco praticadas no ambiente escolar. Segundo Finco e Maciel (2020), em muitas escolas a Educação Física escolar se resume ao ensino dos esportes coletivos de quadra, denominados de "quarteto fantástico": Futsal, Vôlei, Basquete e Handebol. Estes conteúdos são reconhecidos como indispensáveis durante as aulas, sendo mais valorizados e aceitos pelos alunos, como apresentado no relato de um dos professores entrevistados: “[...] o futsal que não pode faltar nas aulas [...]" (P.4).

Outro fator que contribui para a não inserção do conteúdo lutas é a associação à violência. Para Carreiro (2005), o próprio professor desiste de abordar a atividade, pois muitas vezes não consegue esclarecer a si e aos outros (pais, família, escola) sobre 
Inserção das lutas na educação física escolar da cidade de Muriaé-Mg

Nicoly Rocha Ferreira • Júlia Loth Costa • Tassiana Aparecida Hudson • Juliana Fernandes Filgueiras Meireles

a associação errônea entre o conteúdo e a violência. Gomes et al. (2013) alertam que esta se apresenta revestida não apenas de preconceito, mas de concepções limitadas e distorcidas sobre o que a atividade pode significar no contexto pedagógico. Por ter sua prática associada à violência, as aulas de lutas têm sido, no decorrer dos anos, vistas como algo que irá despertar nos alunos o instinto de "briga e confusão".

Contraditoriamente, no presente estudo, durante as entrevistas, os professores não demonstraram como fator limitante o estigma de violência: "[...] Não acho que a violência como todos afirmam, seja o empecilho para ensinar o conteúdo, pois ele seria ensinado de forma educativa [...]" (P1).

Dos professores entrevistados, apenas um demonstrou receio em trabalhar, especificamente com o ensino médio devido à incitação à violência: "[...] tenho o receio de gerar violência entre os alunos por já serem maiores, já existe algumas diferenças entre alguns [...]" (P4).

Outro empecilho apontado por um dos professores e muito recorrente nas aulas de Educação Física é o interesse do professor:

[...] O principal empecilho é a boa vontade de quem está à frente, ou seja, a boa vontade do educador em incluir as lutas no seu planejamento. É muito mais fácil o professor jogar uma bola na quadra e deixar o tempo rolar, não dá trabalho, não precisa se preparar [...] (P.3).

Cabe destacar que o professor citado é praticante e especialista na modalidade caratê e, por isso, abordar o conteúdo Lutas possa ser considerado mais acessível para ele. Todavia, Moura et al. (2019) apontam que são necessárias mais pesquisas referentes ao conteúdo lutas na escola, visando o auxílio dos professores em suas práticas pedagógicas. Apesar da crença dos professores de que é preciso ter uma vivência prévia das lutas como especialista, além da preferência de professores e alunos por outras práticas corporais, sabe-se que todos os conteúdos precisam ser ensina- 
Inserção das lutas na educação física escolar da cidade de Muriaé-Mg

Nicoly Rocha Ferreira • Júlia Loth Costa • Tassiana Aparecida Hudson • Juliana Fernandes Filgueiras Meireles

dos de forma integral, possibilitando ao aluno conhecer e refletir sobre as diversas práticas existentes.

\section{Aspectos pedagógicos e metodológicos}

Embora existam inúmeros estudos que objetivam aprimorar as metodologias de ensino da Educação Física, ainda existem resquícios de fatos ocorridos em momentos distintos da história que se manifestam nas aulas de Educação Física. Desta forma, o repensar da prática docente requer um estudo sobre as questões do passado, para que se possa entender os fatos atuais (FARIAS; SHIGUNOV; NASCIMENTO, 2001).

Nesta categoria, buscamos destacar os conteúdos e as abordagens utilizadas pelos professores entrevistados, a fim de compreender a prática docente dos professores e seus desdobramentos. No ensino da Educação Física escolar existe diversos documentos normativos que visam fundamentar e qualificar a prática docente (BRASIL, 1998; 2017). A utilização dos documentos normativos pelos professores é relatada em algumas falas: "[...] conteúdos que fazem parte dos documentos norteadores [...]" (P.2). "[...] conteúdos presentes nos documentos norteadores [...]" (P.6). "[...] conteúdos trazidos pelos documentos norteadores [...]" (P.7).

Quando questionados sobre a metodologia de ensino, a maioria citou que trabalham do "mais simples" para o "mais complexo", o método analítico e o global: "[...] do mais fácil para o mais difícil [...]" (P.5). "[...] do mais simples para o mais difícil [...]" (P.6). "[...] método global e analíticos [...]" ( P.1). "[...] método analítico e global $[\ldots]^{\prime \prime}(P .7)$.

Sobre as metodologias empregadas pelos professores entrevistados, acredita-se que as formas de ensino foram provenientes da formação desses professores. Libâneo (2016) afirma que os métodos de ensino são as ações do professor pelas quais se 
estabelecem as atividades dos alunos para alcançar objetivos de trabalho docente em relação a um conteúdo específico. O método é o meio com o qual se atinge o propósito de ensinar, em que cada professor desenvolve seu procedimento.

O professor não deve optar por um único modelo para suas aulas, é possível adotar outros métodos, que sejam mais interessantes e adequados para o momento. No presente estudo, 3 dos 7 professores aplicam o método "do mais fácil para o mais difícil" nas aulas de Educação Física, demonstrando uma escassez de conhecimento de outros métodos de ensino. É imprescindível que os professores conheçam as diversas metodologias de ensino para que haja uma aprendizagem efetiva e integral dos alunos (BATISTA; MOURA, 2019)

O método de ensino pode estar relacionado ao ano de formação do professor. No último século ocorreram muitas propostas metodológicas para a Educação Física, e todas essas tendências até hoje influenciam o profissional (BOSCATTO; IMPOLCETTO; DARIDO, 2016). Inúmeras mudanças ocorreram nas teorias da Educação Física com o passar do século, todavia na prática não foram observadas muitas mudanças (OLIVEIRA et al., 2020).

De acordo com os relatos, os professores que se formaram há menos tempo citaram a utilização dos documentos norteadores, provavelmente por terem contato com esses documentos durante o curso e o mesmo não ocorreu com os professores com 26 anos ou mais de formados, talvez por não existirem ainda esses documentos na época da formação. Sobre a metodologia, apenas um professor com a formação mais antiga citou o método utilizado e independente do ano de formação eles apresentaram as mesmas metodologias de ensino, os métodos global e analítico. Este fato pode demonstrar muitas vezes a defasagem nos cursos que abordam algumas metodologias em detrimento de outras. Os métodos utilizados pelos professores estão embasados no conhecimento que possuem e na experiência docente. Em muitos casos, a pouca ou nenhuma utilização de novos métodos se dá ao fato de desco- 
Inserção das lutas na educação física escolar da cidade de Muriaé-Mg

Nicoly Rocha Ferreira • Júlia Loth Costa • Tassiana Aparecida Hudson • Juliana Fernandes Filgueiras Meireles

nhecerem, o que significa a necessidade de atualização pedagógica dos professores de Educação Física (LIBÂNEO, 2016).

Independente da disciplina a ser ministrada, é fundamental que o professor busque atualizar seus conhecimentos. O aluno deve se sentir seguro e reconhecer os objetivos e a importância dos conteúdos para seu processo de formação a fim de formar indivíduos críticos em relação às práticas corporais que os cercam.

\section{Considerações finais}

As lutas fazem parte da cultura corporal, portanto se trata de um conteúdo obrigatório que deve estar presente nas aulas de Educação Física escolar, possibilitando aos alunos o acesso a este campo do conhecimento. A partir dos objetivos propostos, verificou-se que apenas 2 professores desenvolvem o conteúdo lutas de forma completa em suas aulas, e que alguns abordam apenas a forma teórica ou convidam professores especialistas de alguma modalidade para ensinar as lutas.

Neste estudo, foi possível verificar que, apesar da temática lutas ser um conteúdo da Educação Física escolar, seu ensino encontra-se em defasagem. Os professores entrevistados descreveram dificuldades a respeito da inclusão das lutas nas escolas, assim como ressaltaram algumas possibilidades para o seu ensino.

Os fatores restritivos para o ensino das lutas na escola observados nos relatos dos professores foram: falta de conhecimento dos professores sobre o conteúdo, falta de material e espaço adequado e insegurança do professor. Mesmo reconhecendo a existência desses empecilhos, os professores apresentaram algumas possibilidades para aplicação do conteúdo lutas, sendo por meio de jogos de lutas, de aulas teóricas, através de vídeos ou convidando pessoas externas para demonstrar algumas modalidades de lutas. 
Inserção das lutas na educação física escolar da cidade de Muriaé-Mg

Nicoly Rocha Ferreira • Júlia Loth Costa • Tassiana Aparecida Hudson • Juliana Fernandes Filgueiras Meireles

A formação defasada dos professores também foi apontada como um fator limitante, a maioria teve contato com o conteúdo apenas durante a graduação sem procurar por alguma formação continuada. Vale ressaltar que, apenas dois professores relataram que sistematizam o conteúdo nos aspectos conceituais, atitudinais e procedimentais, abordando-o de forma integral.

As lutas precisam ser compreendidas enquanto manifestação da cultura corporal de movimento e que deve ser garantida ao aluno na Educação Física escolar. Além disso, o professor precisa desmistificar o fato de que para ensiná-las seja necessário o domínio de alguma modalidade específica, como treinador ou praticante por exemplo. Estes fatores não são necessários para o objetivo da Educação Física escolar, é preciso que ele conheça os princípios comuns entre as lutas e as diversas formas de ensiná-las nas escolas, para que propicie ao aluno a oportunidade de vivenciá-las e se apropriar dessa prática corporal.

Cabe destacar que o estudo foi conduzido em um local e realidade específicos e incluiu um número reduzido de entrevistados. Embora este seja um aspecto característico de estudos qualitativos, aconselha-se a realização de estudos futuros em diferentes contextos para verificar a inserção do conteúdo lutas nas escolas.

Esta pesquisa possui relevância para a área pois fornece informações pertinentes sobre a inserção desse conteúdo nas escolas, os empecilhos vivenciados e as metodologias utilizadas, a fim de auxiliar a atuação dos professores, bem como nos cursos de formação, nas ações dos gestores e da comunidade escolar, tendo em vista um ensino de qualidade.

\section{Referências}

ALENCAR, Y. O.; SILVA, L. H.; LAVOURA, T. N.; DRIGO, A. J. As lutas no ambiente escolar: uma proposta de prática pedagógica. $\mathbf{R}$.

bras. Ci. e Mov. São Paulo, v. 23, n. 3, p. 53-63, 2015. 
BARDIN, L. Análise de conteúdo. São Paulo: Edições 70, 2011.

BARROS, A. M.; GABRIEL, R. Z. Lutas. In: DARIDO, S. C. (Org.).

Educação

Física Escolar: compartilhando experiências. São Paulo:

Phorte, 2011. p. 74-96.

BATISTA, C.; MOURA, D. L. Princípios metodológicos para o ensino da educação física escolar: o início de um consenso. J. Phys. Educ., Maringá, v. 30, e3041, 2019.

BRASIL. Ministério da Educação. Parâmetros Curriculares

Nacionais: Educação Física. Brasília: MEC/Secretaria de educação fundamental. 1998.

BRASIL. Ministério da Educação. Base Nacional Comum Curricular. Brasília: MEC, 2017.

CARREIRO, E. A. Lutas. In: DARIDO, S. C.; RANGEL, I. C. A. (Org.). Educação física na escola: implicações para a prática pedagógica. Rio de Janeiro: Guanabara Koogan, 2005. p. 244-261. COSTA, J. L.; PEREIRA, L. C. R.; NEVES, C. M.; MEIRELES, J. F. F.; FERREIRA, M. E. C. Inserção da ginástica artística na Educação Física Escolar da cidade de Três Rios-RJ. Pensar a Prática, Goiânia, v. 22, p. 11-13, 2019.

BOSCATTO, J. D.; IMPOLCETTO, F. M.; DARIDO, S. C. A base nacional comum curricular: uma proposição necessária para a educação física? Motrivivência, Santa Catarina, v. 28, n. 48, p. 96-112, 2016.

FARIAS, G. O.; SHIGUNOV, V.; NASCIMENTO, J. V. Formação e desenvolvimento profissional dos professores de Educação Física. In: SHIGUNOV, V.; SHIGUNOV NETO, A. (Orgs.). A formação profissional e a prática pedagógica: ênfase nos professores de Educação Física. Londrina: O Autor, 2001. p.19-53.

FINCO, M. D.; MACIEL, J. S. Kabaddi na escola: conteúdo de ensino para professores de educação física. Pensar a Prática, Goiás, v. 23, 2020. 
FONTANELLA, B. J. B.; RICAS, J.; TURATO, E. R. Amostragem por saturação em pesquisas qualitativas em saúde: contribuições teóricas. Cadernos de Saúde Pública, Rio de Janeiro, v. 24, n. 1 , p. 17-27, 2008.

GOMES, N. C.; BARROS, A. M.; FREITAS, F. P. R.; DARIDO, S. C.; RUFINO, L. G. B. O conteúdo das lutas nas séries iniciais do ensino fundamental: possibilidades para a prática pedagógica da Educação Física Escolar. Motrivivência, Florianópolis, n. 41, p. 305-320, 2013.

LIBÂNEO, J. C. A teoria do ensino para o desenvolvimento humano e o planejamento de ensino. Educativa, Goiânia, v. 19, n. 2, p. 353-387, 2016.

LOPES, R. G. B.; KERR, T. O. O ensino das lutas na Educação Física escolar: uma experiência no ensino fundamental. Motrivivência, Florianópolis, v. 27, n. 45, p. 262-279, 2015.

LOPEZ, P. C. G.; GOLIN, C. H.; RIBEIRO, E. A. G. O conteúdo lutas no ensino médio: discursos dos professores de Educação Física da fronteira Brasil-Bolívia. Pensar a Prática, Goiás, v. 22, n. 19, 2019.

MOURA, D. L.; SILVA JUNIOR, I. A. L.; ARAUJO, J. G. E.; SOUSA, C. B.; PARENTE, M. L. C. O ensino de lutas na Educação Física Escolar: uma revisão sistemática da literatura. Pensar a Prática, v. 22, Goiás 2019.

NASCIMENTO, P. R. B.; ALMEIDA, L. A tematização das lutas na Educação Física Escolar: restrições e possibilidades. Movimento, Rio Grande do Sul, v. 13, n. 3, p. 91-110, 2007.

NUNOMURA, M. Ginástica Educacional ou Ginástica Olímpica. Revista Motriz, Rio Claro, v. 4, n. 1, 1998.

OLIVEIRA, P. V.; MACIEL, L. F. P.; IAOCHITE, R. T.; SALLES, W. N.; NASCIMENTO, J. V.; FOLLE, A. Autoeficácia no ensino superior e satisfação com as experiências acadêmicas: percepções de estudantes de educação física. Movimento, Porto Alegre, v. 26, n. e26087, p. 1 - 16, 2020. 
OLIVEIRA, W. L. C.; SANTOS, R. C.; VERLI, M. V. A.; GOMES, M. K. M.; BENASSI, R.; GONÇALVES, L. C. O.; NETO, A. M. M. A inserção dos esportes de combate nas aulas de educação física escolar: uma visão atual. Revista Panorâmica On-Line, Barra do Garças, v. 22, p. 93 - 106, 2017.

PEREIRA, M. P. V. C.; MARINHO, A.; FOLLE, A.; MOTA, I. D.; FARIAS, G. O. Jogo como estratégia de ensino: tematizando a prática de lutas na escola. Retratos da Escola, Brasília, v. 14, n. 28, 2020.

RUFINO, L. G. B.; DARIDO, S. C. A produção científica em pedagogia do esporte: análise de alguns periódicos nacionais. Conexões: Educação Física, Esporte e Saúde, Campinas, v. 9, n. 2, p. 130152, 2011.

RUFINO, L. G. B.; DARIDO, S. C. O ensino das lutas na escola: possibilidades para a educação física. Revista da educação física UEM, Maringá, v. 26, n. 4, p. 505-518, 2015.

THOMAS, J. R.; NELSON, J. K.; SILVERMAN, S. J. Métodos de pesquisa em atividade física. 6ed. Artmed, Porto Alegre, 2012.

UENO, V. L. F.; SOUZA, M. F. Agressividade, violência e Budo: temas da Educação Física em uma escola estadual de Goiânia. Pensar a Prática, Goiânia, v.17, n.4, 2014.

\section{Publisher}

Universidade Federal de Goiás. Faculdade de Educação Física e Dança. Publicação no Portal de Periódicos UFG. As ideias expressadas neste artigo são de responsabilidade de seus autores, não representando, necessariamente, a opinião dos editores ou da universidade. 